\title{
Research on Characteristics of Equivalent Sequence Impedance of Doubly Fed Induction Generator Wind Turbine
}

\author{
Xiang Lia, Yongning Chi, Haiyan Tang and Xinshou Tian \\ Department of Renewable Energy, China Electric Power Research Institute, Beijing, China \\ awishx@126.com
}

Keywords: wind energy, equivalent sequence impedance, relay protection, PSCAD simulation.

\begin{abstract}
Wind generation is widely utilized today as a promising form. As the major type of wind turbines, doubly fed induction generator (DFIG) wind turbines have been widely used. Now great attention is paid to the relay protection of power systems integrated with wind power of large capacity. Based on fault analysis, the equivalent sequence impedance is a key factor of protection strategy. In this paper, the model of DFIG wind turbines is built in PSCAD/EMTDC software. Then the characteristics of sequence impedance are calculated and analyzed at length. And the relay protection method is discussed as the conclusion.
\end{abstract}

\section{Introduction}

Wind generation is widely utilized today due to its renewable characteristics and environmental friendliness. Along with the enlargement of capacity of wind power, its integration affects both secure operation of power grid and correct action of relay protection evidently. Now great attention is paid to the secure protection of wind power increasingly.

As the major type of wind turbines, doubly fed induction generator (DFIG) wind turbines have been widely used. The analysis of fault characteristics of DFIG wind turbines is the premise of the protection technology. Furthermore, the sequence impedance is a key factor affecting the relay protection strategy. The wind farm belongs to typical weak power-feed system. Due to the control strategy, the positive and negative sequence impedances of wind farm are not equal, which directly affects the protection elements. And the zero sequence impedance also plays an important role in ground fault protection. The fault current felt by protections of wind farm is almost the total zero-sequence component of the fault current. So it is crucial to analyze the sequence impedance.

Several promising methods for FRT based on crowbar protection circuit have been provided, and some FRT control strategies considering rotor excitation control have been developed in [1-5]. Some experts focus on the transient characteristics of wind turbines and its impacts on transient stability of power system [6-7]. However, rare papers consider the sequence impedance characteristics of DFIG, which is a crucial element to the protection strategy of wind turbine. Without the analysis of sequence impedance, the influence factors of fault currents are unclear.

In this paper, the electromagnetic transient model of DFIG wind turbine system is modelling in PSCAD, including the wind turbine, the DFIG and its control system. And the simulation of four types of fault are made and compared. The characteristics of sequence impedance, including the positive, negative and zero sequence impedances are calculated based on symmetrical component method. And the relay protection strategy is discussed as the conclusion.

\section{Model of DFIG System}

An ideal power system is used when building the electromagnetic model in PSCAD/EMTDC software. A DFIG is connected to the $20 \mathrm{kV}$ AC system through a step-up transformer $(20 \mathrm{kV} / 690 \mathrm{~V})$. Suppose that the rated load and wind speed are constant, fault simulation can be made on the connecting line.

A DFIG of 2MW, 4 poles, $690 \mathrm{~V}$ is used and its major parameters are as follows: the corresponding power coefficient $\mathrm{Cp}=0.28$, the cut-in wind speed $\mathrm{vmin}=6 \mathrm{~m} / \mathrm{s}$, the cut-out wind speed vout $=21 \mathrm{~m} / \mathrm{s}$, 
the radius of the blades $\mathrm{Rb}=25 \mathrm{~m}$, the turn ratio of stator to rotor $\mathrm{rsr}=0.3$, the stator resistance $\mathrm{Rs}=0.0054 \mathrm{pu}$, the rotor resistance $\mathrm{Rr}=0.0061 \mathrm{pu}$, the friction coefficient $\mathrm{D}=0.001$, the excitation reactance $\mathrm{Xe}=4.5 \mathrm{pu}$, the leakage reactance $\mathrm{Xs}=0.10 \mathrm{pu}, \mathrm{Xr}=0.11 \mathrm{pu}$ and the $\mathrm{DC}$ capacitor $\mathrm{C}=7800 \mu \mathrm{F}$.

\section{Calculation of Equivalent Sequence Impedance}

As a type of nonconventional power source, the integration of wind power cannot always adapt to the traditional principle of relay protection which is based on synchronous motor and three-phase symmetrical system. Fault analysis is the foundation of the design and setting calculation of relay protection strategy.

And the sequence impedance is a more important electric parameter influencing the relay protection. The function of control system of wind farm causes the inequality of positive and negative sequence impedance, which directly affects the choice of relay protection elements; and the zero sequence also plays an important role in the protection of ground fault. So it is crucial to study on the characteristics of sequence impedance of wind farm.

In this paper, the sequence impedance is calculated in PSCAD/EMTDC software based on symmetrical component method. The Fourier transform is used to transfer the three phase parameters into three sequence ones. The negative and zero sequence impedances can be acquired by the ratio of sequence voltages to sequence currents after the fault. But when calculating the positive sequence impedance, the used voltage should be the voltage after fault minus the voltage before fault.

In the actual projects, typical faults include single-phase ground fault, two-phase short-circuit fault, two-phase short-circuit ground fault and three-phase short-circuit ground fault. The time to apply fault can be set as $0.4 \mathrm{~s}$. The durations of faults are all $0.15 \mathrm{~s}$.

The results can be seen as follows.

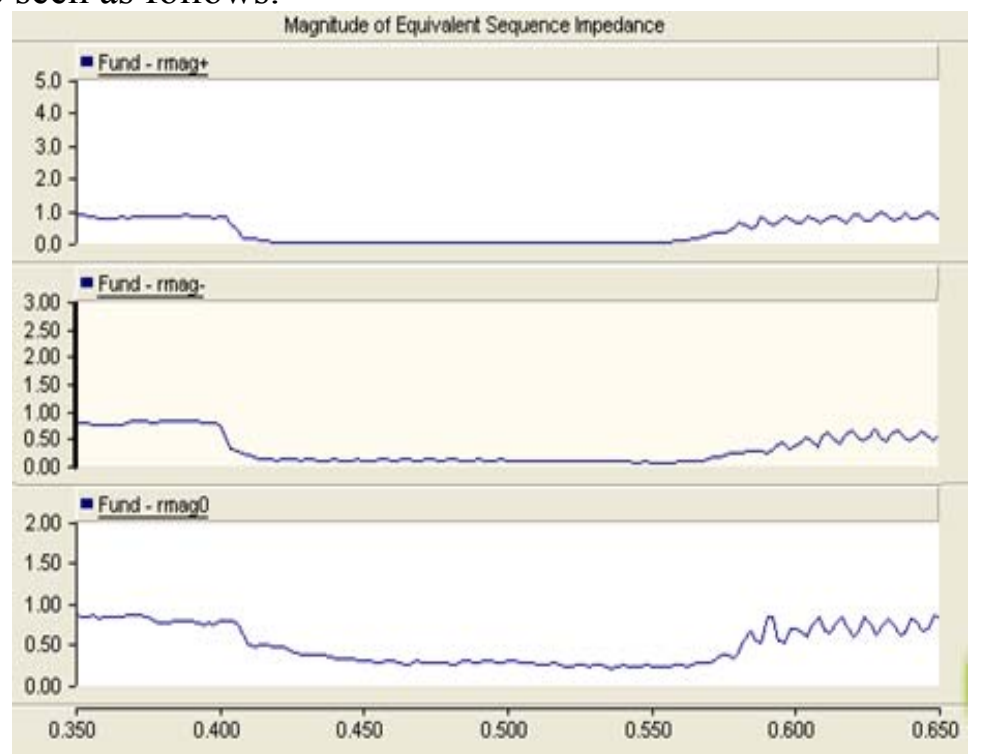

Fig.1 The positive, negative and zero sequence in single-phase ground fault case.

The equivalent positive, negative and zero sequence impedance in single-phase ground fault case are depicted in Fig.1. It can be seen that before the fault is applied, the positive sequence impedance is greater than the negative and zero sequence impedance. During the fault, the positive and negative sequence impedance are decreased. The reason is that after the fault, the speed of wind turbine exceeds the synchronous speed and the fault isolates the turbine from the system. In nature, the change of slip ratio affects the turbine's positive sequence impedance. The zero sequence impedance is roughly unchanged, due to the relatively stable grid structure of wind farm. 


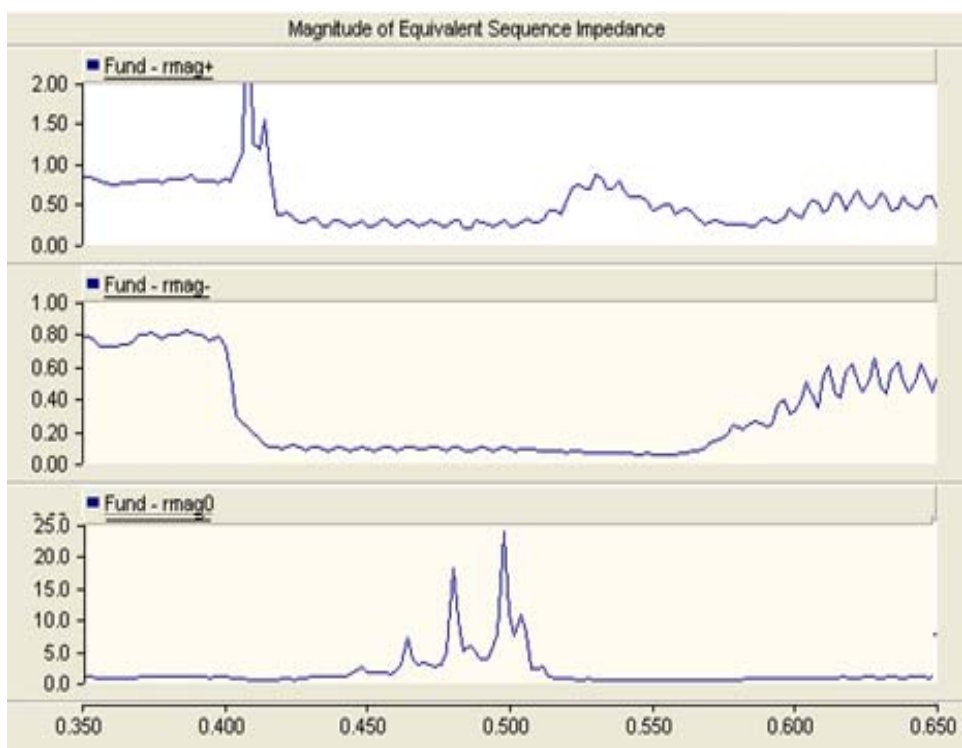

Fig.2 The positive, negative and zero sequence in two-phase short-circuit fault case.

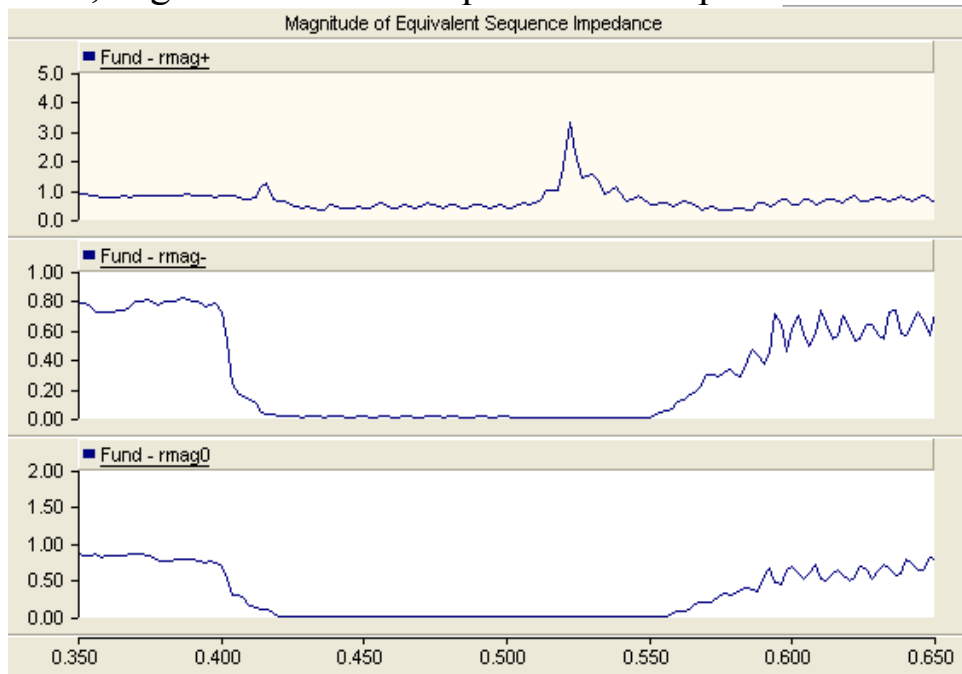

Fig.3 The positive, negative and zero sequence in two-phase ground fault case.

As demonstrated in Fig.2 and Fig.3, the trends of positive and negative sequence impedance in these two cases are similar. During the fault, the positive sequence impedances change slightly while the negative sequence impedances decline to zero. The main difference is the zero sequence impedance. In two-phase short-circuit ungrounded fault case, it increases and becomes large. But in ground fault case, it decreases and becomes zero finally. The reason is that the passage of zero sequence current components only exists in ground fault.

In three-phase ground fault case, the positive sequence impedance changes a little and keeps roughly constant. And the concept of negative and zero sequence impedance does not exist in this case. In other words, the negative and zero ones are infinite. So for simplicity, the results of three-phase ground fault case are omitted here.

\section{Relay Protection Strategy}

When a wind farm is connected to the power system, the normal practice is to regard it as a combination of equivalent synchronous machines. However, obvious error is brought to the relay protection calculation by doing this. Thus it is crucial to analyze the characteristics of wind farm and understand its influence on the arithmetic.

Based on the equivalent sequence impedance, analysis of faults' influencing factor and relaying protection arithmetic can be worked out. Adaptive instantaneous trip current protection strategy can be adopted because of its reliability, directivity, automaticity, suitability and optimal protection domain. The setting value of this protection arithmetic can be expressed as follows [1]: 


$$
I_{\text {act }}=\frac{K_{\mathrm{rel}} K_{\mathrm{k}} E_{\mathrm{s}}}{Z_{\mathrm{s}}+Z_{1}}
$$

where Krel is the reliability coefficient that is often assigned 1.2 1.3; Kk is the coefficient of fault type; Es is the equivalent potential of system; and the two $Z$ parameters are internal impedances of the line; $\mathrm{Kk}$ and $\mathrm{Z}$ are two variables which need to be calculated instantaneously.

In the expression of the current's setting value, the coefficient of fault type and the internal impedance of the line are two variables which need to be calculated instantaneously. In this protection strategy, the fault type can be determined by phase current criterion. And the internal impedance can be computed on the basis of symmetrical component method. The DFIG system can be regarded as a linear circuit at the time when the fault is applied. That's why this arithmetic is considered to be reasonable.

\section{Conclusion}

Along with the increase of wind power generation, people are concerned about the safe and stable operation of wind power system. In this paper, the electromagnetic transient model of DFIG wind turbine system is modelling in PSCAD software. The four types of fault are simulated and compared. Then the characteristics of sequence impedance are calculated based on symmetrical component method. And the relay protection strategy which is greatly influenced by sequence impedance is discussed as the conclusion. The adaptive instantaneous trip current protection arithmetic is suitable for DFIG system.

\section{Acknowledgements}

This work is sponsored by National High Technology Research and Development of China (863 program) under Grant 2013AA050601, National Natural Science Fund U1510208 and State Grid Corporation S\&T Project named Simulation and Analysis of Renewable Energy Generation and Grid Wideband Coupling Mechanism.

\section{References}

[1] Yang Guosheng, Li Xin, Zhou Zexin: Impacts of wind farm on relay protection for distribution network and its countermeasures, Power System Technology, Vol. 33(11) (2009), p. 87-91.

[2] Feng Shuanglei, Zhao Haixiang, Ren Puchun, et al: PSCAD/EMTDC based simulation study on dynamic model of doubly-fed variable speed wind turbine, Power System Technology, Vol. 31(17) (2007), p. 31-35.

[3] Johan Morren, Sjoerd W.H.de Hann: Short-circuit current of wind turbines with doublyfed induction generator, IEEE Transactions on Energy Conversion, Vol. 22(1) (2007), p. 174-180.

[4] Zhang Baohui, Li Guanghui, Wang Jin, et al: Affecting factors of grid-connected wind power on fault current and impact on protection relay, Electric Power Automation Equipment, Vol. 32(2) (2012), p. 1-8.

[5] Ma Zhiyun: Transient Analysis of Electric Motor. Edited by China Electric Power Press, Beijing (1998), in press. 